\title{
PEMBAHARUAN HUKUM AGRARIA NASIONAL YANG BERKEADILAN SOSIAL
}

\author{
Aris Yulia \\ Universitas Sahid, Jakarta \\ aris_jnlia@yanoo.com
}

ABSTRAK

Sumber daya alam di Indonesia secara garis besar dibagi menjadi empat, yakni: bumi, air, mang angkasa, dan kekayaan alam yang terkandung di dalamnya. Amanat Pasal 33 ayat (3) UUD NRI 1945 untuk mengelola sumber daya alam tersebut untuk dipergunakan sebesar-besarnya untuk kemakmuran rakyat. Fakta yang terjadi, pendistribusian sumber daya agraria tidak seimbang dan belum mencerminkan keadilan sosial. Dalam hal ini perlu dilakukan pembaharuan hukum agraria nasional yang berkeadilan sosial.

Kata Kunci: Hukum Agraria, Berkeadilan Sosial, Pembaharuan

\section{ABSTRACT}

Natural resources in Indonesia are broadly divided into four, namely: land, water, space, and natural wealth contained in it. The mandate of Article 33 paragraph (3) of the 1945 Constitution of Republic Indonesia to manage these natural resources is to be used as much as possible for the prosperity of the people. In fact, the distribution of agraria resources is not balanced and has not reflected social justice. In this case it is necessary to renew national agraria law that has social justice.

Keywords: Agraria Law, Social Justice, Renewal

\section{PENDAHULUAN}

Pasal 33 ayat (3) UUD NRI 1945 mengamanatkan bahwa bumi, air dan kekayaan alam yang terkandung di dalamnya dikuasai oleh negara dan dipergunakan untuk sebesar- besarnya kemakmuran rakyat. Berdasarkan amanat ini, maka negara memiliki tanggung jawab untuk memastikan bah ' va seluruh sumber daya alam harus dikuasai dan dipergunakan untuk kemakmuran rakyat. Berdasarkan Pasal 2 ayat (3) Undang-Undang Nomor 5 Tahun 1960 mengatur mengenai wewenang negara yang bersumber pada hak menguasai negara dan harus dipergunakan untuk mencapai sebesar-besar kemakmuran rakyat. Tanah merupakan salah satu objek hukum agraria yang dinilai sangat strategis. Hal ini dikarenakan hampir setiap aktivitas kehidupan manusia terkait dengannya. Dapat disimpulkan bahwa tanah merupakan suatu objek yang sangat dibutuhkan oleh setiap orang.

Kebutuhan masyarakat terhadap tanah pada saat sekarang ini tidak sesuai dengan ketersediaan tanah yang terbatas. Berdasarkan kondisi ini maka pemerintah hams mengatur distribusi perolehan tanah agar pemenuhan kebutuhan masyarakat terhadap tanah dapat terpenuhi. Tanah seyogyanya digunakan untuk memenuhi kebutuhan masyarakat.

Pendistribusian kepemilikan tanah kepada masyarakat agar, tercipta dan menjamin kesejahteraan bersama tidak terlaksana derrgan baik dan tidak mencerminkan keadilan sosial sebagaimana amanat didalam Pancasila. Hal ini terceimin dari timpangnya kepemilikan tanah di Indones'ia. 
Berdasarkan data Konsorsium Pembaruan Agraria, 0,2 \% penduduk negeri ini menguasai 56 $\%$ aset nasional yang sebagian besar dalam bentuk tanalr (Pernyataan Sikap Hari Tani Nasional, 2017). Pengalihan orientasi ftrngsi tanah yang cenderung berorientasi untuk mengejar pertumbuhan pembangunan dan intlutrilisasi mengakibatkan beralili- ftrngsinya tanah-tanah yairg semula digunakan untuk pertanian, kini bei'alih ftrngsi menjadi kegunaan yang lain. Kenyataan yang ada di lapangan selama ini, pendistribusian sumber daya agraria yang tidak seimbang dan tidak mencirikan keadilan sosial menjadi landasan dalam pembaharuan Hukum Agraria Nasional yang berkeadilan sosial.

\section{METODE PENELITIAN}

Metode Penelitian yang digunakan adalah metode penelitian hukum/normatif. Yakni suatu proses penelitian yang digunakan untuk menemukan suatu aturan hukum maupun doktrin-doktrin hukum yang menjawab permasalahan yang dilradapi. Penelitian hukum yang dilakukan dengan mengolalr dan menghinakan data sekunder untuk menghasilkan argumentasi, teori, atau konsep baru sebagai preskripsi dalam menyelesaikan masalah yarrg dihadapi.

\section{HASIL PENELITIAN DAN PEMBAHASAN}

Istilah agraria berasal dari bahasa Yunani, berasal dari kata Ager yang berarti ladang atau tanah. Sedangkan menurut kamus bahasa Indorresia, agraria adalah Urtisan pertanian atau tanah pertanian, juga urrisan pemilikan tanah (Harsono, 2005). Sedangkan di dalam Undarrg- Undang Nomor- 5 Tahun 1960 tentang Dasar Pokok- Pokok Agraria (UUPA), terdapat dua jenis penger-tian agraria, yakni (Chornzah, 2004):

1. Secara luas, terdapat didalam Pasal 1 ayat (2) UUPA, yang meliputi brrmi, air dan ruang arrgkasa. '

2. Secara sempit terdapat dalanr pasal 4 ayat (1) UUPA.

Beberapa ahli hukum juga memberikan perrdapat mengenai pengertian hukum agraria. Subekti berpendapat bahwa hukum agraria adalah keseluruhan ketentuan,- ketentuan hukum, baik hukum perdata, maupun hukum tata negara maupun hukum tat.a usaha negara yang mengaftrr hubungan-hubungan antara orang termasuk badan hukum dengan, bunri, air dan ruang angkasa dalam, seluruh wilayah negara dan, mengatur- pula wewenang-wewenang yang bersumber pada hubunganhubungan tersebut.

Uftecht berpendapat bahwa hukum agraria dan hukum tanah menjadi bagian hukum tata usaha negara yang menguji perhubungan-perhubungan hukum, istimewa yang diadakan akan memungkinkan para pejabat yang bertugas mengurus soal-soal tentang agraria melakukan tugas mereka itu. 
Secara filosofis pembentukan UUPA ditujukan untuk mewujudkan apa yang digariskan dalam Pasal 33 ayat (3) Undang-undang Dasar Negara Republik Indonesia Tahun 1945, bahwa "bumi, air dan kekayaan alam yang terkandung di dalamnya dikuasai oleh Negara dan dipergunakan untuk sebesar-besarnya kemakmuran rakyat". Pernyataan ini berarti merupakan suatu kewajiban agar bumi, air, dan mang angkasa dan kekayaan alam yang diletakkan dalam kekuasaan negara untuk mewujudkan kesejahteraan seluruh rakyat Indonesia. Kesejahteraan yang dimaksudkan adalah kesejahteraan lahir batin, adil dan merata bagi seluruh rakyat Indonesia (Hatta, 2005).

Bumi, air, dan mang angkasa termasuk mempakan kekayaan alam di Indonesia. Sumber daya alam ini mempakan bagian dari kekuasaan negara. Hal ini ditegaskan di dalam Undang-Undang Dasar Tahun 1945. Undang-Undang Dasar 1945 Pasal 33 ayat (3) yang menyatakan bumi, air dan kekayaan alam yang terkandung didalamnya dikuasai oleh Negara dan dipergunakan untuk sebesar-besarnya kemakmuran rakyat.

Pengelolaan dan distribusi manfaat dari sumber daya alam ini, sangat erat kaitannya dengan peraturan yang ada didalam TAP MPR IX Tahun 2001 tentang Pembaharuan Agraria dan Pengelolaan Sumber Daya Alam. Secara umum, ini mempakan pencapaian dan penyataan eksplisit MPR bahwa yang paling penting dan dibutuhkan pemerintah dalam berkomitmen untuk pembaharuan pengelolaan sumber daya alam dan pembaharuan agraria. Hal ini menghamskan Negara dan pemerintah untuk mengkaji, mencabut dan merevisi semua peraturan perundang-undangan mengenai tanah dan sumbersumber agraria lainnya, serta menyelesaikan konflik agraria yang ada saat ini secara adil dan lestari. TAP MPR ini mempakan alat yang paling ampuh dalam proses reformasi dan mempakan penyempurnaan perundang-undangan agraria di Indonesia (Chip Fay, 2005).

Sebelum diterbitkannya UUPA, terjadi dualisme landasan dalam membuka hak atas tanah, yakni terdapat pada pasal 51 ayat 7 IS, pada Stb 1872 No. 117 tentang Agraris Eigendom Recht yaitu memberi hak eigendom (hak milik) kepada orang Indonesia, dan hal yang disamakan dengan hak eigendom yang terdapat pada buku II BW yang diberikan kepada mereka yang bukan orang Indonesia. Dengan diberlakukannya UUPA dapat dikatakan telah tercapai suatu kodifikasi dan unifikasi hukum agraria di Indonesia.

Penerbitan UUPA Nomor 5 Tahun 1960 pada tanggal 24 September 1960 menyeragamkan dualismee aturan yang mengatur hak- hak tentang tanah di Indonesia. Maka dengan adanya dualismee aturan yang mengatur tentang hak-hak tanah untuk menyeragamkannya pada tanggal 24 september 1960 diterbitkan Undang-Undang Pokok Agraria No. 5 Tahun 1960 pada lembar Negara No. 104/1960.

Pemahaman mengenai tujuan dari hukum agraria nasional tersebut merupakan suatu hal yang sangat penting dalam menentukan isi dari peraturan perundang-undangan di bidang sumber daya alam atau agraria. Tujuan hukum agraria tersebut hanya dapat dilaksanakan dengan hak menguasai negara yang dijabarkan dalam Pasal 2 ayat (2) UUPA. Dalam pasal tersebut diatur bahwa hak menguasai negara berisikan wewenang untuk:

1. Mengatur dan menyelenggarakan peruntukan, penggunaan, persediaan dan pemeliharaan bumi, air dan ruang angkasa; 
2. Menentukan dan mengatur hubungan-hubungan hukum antara orang-orang dengan bumi, air dan ruang angkasa؛

3. .Menentukan dan mengatur hubungan-hubungan hukum antara orang-orang dan perbuatan-perbuatan hukum yang mengenai bumi, aii. dan ruang angkasa.

Undang-Undang Pokok Agraria No.5 Tahun 1960 merupakan Undang-Undang yang mengatur 197 juta hektar wilayah daratan Indonesia. Undang-Undang ini menuntun pemerintah dalam pengakuan dan pemberian 7 jenis hak atas tanah dan 3 tambahan jenis hak atas pemanfaatan sunrber daya alam. Dalam Pasal. 16 ayat (1) UUPA menyatakan hak- hak atas tana.h sebagaimana yang dimaksud dalam Pasal 4 ayat (1) adalah:

1. Hak milik;

2. Hak guna usaha;

3. Hak guna bangunan;

4. Hak pakai;

5. Hak sewa;

6. Hak membuka tanah;

7. Hak memun^it hasil hutan;

8. Hak-hak lain yairg tidak teimasuk dalam hak-hak tersebut diatas yang akan ditetapkan dengair Undang-Undang serta hak-hak yang sifatnya sementara sebagai yang disebutkan dalam Pasal 53.

Dalam Pasal 16 ayat (2) LUPA menyatakan hak-hak atas air dan ruang angkasa sebagaimana yang dinraksud dalam Pasal 4 ayat ( $3 \mathrm{j}$ adalah:

1. Hak guna air;

2. Hak pemeliharaan dan penangkapan i.kan;

3. Hak guna mang angkasa.

Hak yang paling kuat dan paling penuh dari semua jenis Irak adalah Hak Milik, dan diantara berbagai jenis hak atas tanah yang telah diatur lebih lanjut dalam Peraturan Pemerintah Noirror 40 Talrun. 1996 adalah Hak Guna Usaha, Hak Guna Bangunan, dan Hak Pakai, serta dalam Peraturan Pemerintah Nonror 24 Tahun 1997 tentang Pendaftaran Tairah mengatur konsep dan prosedur untuk pengakuan atau penrberian berbagai jenis hak atas tanalr. Dalam peraftrran ini, tanali dibagi dalam 2 jenis, yakni: Tairah Bekas Hak Adat, yakni hak lanra yang telalr diakui keberadaannya jauh sebelum adanya UUPA; dan Hak lainnya yang diberikan dengan aturan yang lebih rinci, yaitu Hak Guna Bangtman, Hak Guna Usaha atau Hak Pakai berdasarkan pernrolronan hak dengan subjek .Irak atas tanalr, yang terdiri dari orang per-orang dan badan lrukum (Chip Fay, 2005).

Penguasaatr tanah oleh penguasaha sangat berbanding terbalik dengan penguasaan lahan olelr petani. Petairi Indonesia hanya menguasai 8.9juta lra lahan (Susyanti, 2010). Luas lahan pertanian tersebut sangat tidak ideal jika dibandingkan dengan jumlalr petani, yang mencapai angka 39 juta orang. Penyempitan lahan pertanian ini disebabkan olelr makin maraknya konversi lahan pertanian ke non pertanian. Badan Pertanahan Nasional (BPN) mencatat bahwa sejak tahun 1992-2002 laju konversi lahan pertanian pertalrun adalah 11.0 ribu lra dair meningkat menjadi 145 ribu ha selama empat talrun terakhir (Susyanti, 2010). Konversi lahan pertaniair ini sangat tidak sesuai dengan esensi UUPA. UUPA menghendaki usaha-usaha dalam bidang agraria diatui. unftrk meninggikan produksi dan kemakmuran rakyat serta menjamim derajat hidup yang baik bagi setiap WNI (Harsono, 2005).

Badan Pusat Statistik menyatakan pada Tahun 2009, terdapat sebanyak 56,5\% atau sekitar 39 
juta petani hanya menguasai lahan pertanian kurang dari 0,5 ha, sedangkan idealnya menurtit UndangUndang Nomor 56 Tahun 1960 tentang Penetapan Luas Lahan Petanian adalah 2 ha. Seharusnya peiuerintah lebih memprioritaskan kebijakan untuk kepentingan masyarakat tani. Kebijakan pemerintah sehatusnya lebih berpihak dan mengutamakan kaum tani unrtik meningkatkan kesejahteraan bagi petani melalui peningkatan penguasaan luas lahan daripada mengkonversikan lahan pertanian menjadi lahan industry.

Membangun hukum agraria yang berkeadilan sosial didasari dengan keseimbangan antara kepentingan individu dan kepentingan umum. Kepentingan individu harus dibatasi oleh kepentingair umum yang merupakan firngsi sosial dari liak atas tanah. Pembatasan hak menguasai negara menurut Undang-Undang Dasar Negara Republik Indonesia Tahurr 1945 berprinsip bahwa hal yang diadu oleh negai'a tidak boleh berakibat terhadap pelanggaran hak dasai. manusia sebagaimana yang dijamin oleh Undang-Undang Dasar Negara Republik Tahun 1945. Pembatasan hak juga bertujuan untuk kemakmuran rakyat unhrk tercapainya nilai-nilai dalam pancasila, yakni diantaranya adalah keadi-lan sosial.

Pembaharuan terhadap hukum agaria nasional hartis merefleksikan nilai-nilai pancasila, yakni nilai keadilair sosial. Rujukan terhadap pembahaiuan hukum agraria nasional iiri dapat dilihat dalam kesimpulan Seminar Hulmm Nasional rv (26-30 Maret 1979) mengenai Penjabaran Panc.asila Dalam Hukum menyimpulkan bahwa pencerminan nilai-nilai Pancasila dalam perundang-undangan, yaitu (Abdurrahman, 1995):

1. Pancasila yang mengandung nilai-nilai kejiwaan bangsa Indonesia merttpakan dasar tertib hukum Indonesia, pedoman dan petunjuk arah perkembangannya dengan systein yang terbuka dan adalah batu ujian mengenai kepatutan dan peiundang- undangan

2. Dalam menyusun undang-undang, pembenhrk undang-undang perlu dengan tepat menunjukan nilai-nilai pancasila yang mendasari ketentuan undang-undang itu. Dengan demikian, peraturan hukum merupakan pelaksanaan undang-undang im tidak boleh mengandung hal-hal yang bertentangan dengan pancasila.

3. Pencerminan nilai pancasila di dalam perundang-undangan merttpakan hakikat pembenhrkan sistem hukum nasional

Beberapa prinsip Pembaharuan hukum agraria nasional juga terdapat di dalam TAP MPR No.IX/MPR/2001, diantaranya:

1. Memelihara dan mempertahankan keutuhan NKRI:

2. Menghormati dan menjunjung tinggi Hak Asasi Manusa؛

3. Menyejahterakan rakyat, teiutama melalui peningkatan kualitas sumber daya manusia Indonesia:

4. Mewujudkan keadilan tennasuk kesetar.aan gender dalam penguasaan, pemilikarr, penggunaan, pemanfaatan dan pemeliharaan sumber daya agraria/sumber daya alam؛

5. Mengupayakan keseimbangan hak dan kewajiban negara, pemerintah (pusat, daerah provinsi, kabupaten/kota dan desa atau yang setingkat (masyarakat atau individu')؛

6. Mewujudkan keadilan dalam penguasaan, pemilikan, penggunaan, pemanfaatan dan pemeliharaan sumber daya agraria؛

7. Memelihara keberlanjutan, yang dapat memberi manfaat yang optimal baik unhik generasi sekarang maupun generasi mendatang dengan tetap memperhatikan daya tampung dan daya dukung lingkungan؛ 
8. Melaksanakan fungsi sosial, kelestarian dan ftrngsi ekologis sesuai dengan kondisi sosial budaya setempat؛

9. Meningkatkan keterpaduan dan koordinasi antar sector pembangunan dalam pelaksanaan pembaruan agraria dair pengelolaan sumber, daya alam؛

10. Mcngalmi dan menghormati Irak masyarakat hukum adat darr keragaman budaya bangsa atas sumber daya agraria dan sumber daya alam؛

11. Mengupayakan keseimbangan hak dan kewajiban negara, pemerintalr (pusat, daerah, provinsi, kabupaten/kota dan desa atau yang setingkat), masyarakat dan individu؛

12. Melaksanakan desentral-isasi berupa pembagian kewenangan di tingkat nasional, daerah provitrsi, kabupaten/kota dan desa atau yatrg setirrgkat), masyarakat darr individu؛

13. Melaksanakan desentralisasi berupa pembagian kewenarrgan di tingkat nasional, daeralr provinsi, kabupaten/kota, dan desa atatr yang setingkat berkaitarr dengan alokasi dan manajemen sumber, daya agraria dan sumber daya alam.

\section{KESIMPULAN DAN SARAN}

Pembaharuan Hukum Agraria Nasional yang Berkeadilan Sosial merupakan sesuaftn yang perlu dan penting dilaksanakan. Hal ini terjadi karena besarnya ketimpangan masyarakat terhadap penguasaan tanaln, terlilnat dari segelintir masyarakat menguasai tanah lebiln dari setengah total luas lahan tanaln di Indonesia. Hal ini tentu sangat bertentangan dengan keadilan sosial dan amanat dalam Undang-Undang Dasar* Negara Republik Indonesia talnrrn 1945 dan tujuan hukum agraria nasional bahwa kekayaan alam merupakan sebesar-besarnya untuk kemakmuran rakyat. Berdasarkan hal di atas, maka perlu dilakukan kajian ularrg dan dilakrrkarr perubahan/ revisi terhadap perundangundangan yang berkaitan derrgan hukum agraria nasional agar, lebih mencerminkan hukum agraria nasional yang berkeadilan sosial.

\section{DAFTAR PUSTAKA Artikel}

\section{dalam jurnal publikasi}

CYhp עוע k Ha. PAaVi, Kerungku Hukum Negara dalam Mengatur Agraria dan Kehutanan Indonesia: Mempertanyakan Sistem Ganda Ke Ivenarrgan atas Penguasaan Tanah.: ICRAF Southeast Asia Working Paper, No.2005 3 
Buku

Boedi Harsono, Hukum Agraria Indonesia: Sejarah Pembentukan Undang-undang Pokok Agraria, Isi dan Pelaksanaannya, Jakarta: Djambatan, 2005.

Ali Achmad Chomzah, Hukum Agraria (Pertanahan Indonesia), Jakarta: Prestasi Pustaka, 2004.

Mohammad Hatta, Hukum Tanah Nasional dalam Perspektif Negara Kesatuan, Cetakan I. Yogyakarta:

Media Abadi, 2005

Nur Sri Susyanti, Bank Tanah: Alternatif Penyelesaian Masalah Penyediaan Tanah Untuk Pembangunan Kota Berkelanjutan, Makasar: A.S. Publishing, 2010.

Abdurrahman. Beberapa Aspekta Tentang Pembangunan Hukum Nasional. Bandung : P.T.

Citra Aditya Bakti.

\section{Website/ Laman}

Komisi Pembaruan Agraria. 2016. Pernyataan Sikap Hari Tani Nasional.

http: 7www.kpa.or.idhews/blo $\underline{\text { ^/pemvataan-sikap-hari-tani-nasional-2016 }}$ 